\title{
Clinical predictors of successful and earlier pleurodesis with a tunnelled pleural catheter in malignant pleural effusion: a cohort study
}

\author{
Pen Li MD, Alison Graver MD, Sarah Hosseini MD, Sunita Mulpuru MD MSc, Lorraine Cake BScN, \\ Lynn Kachuik BScN MSc, Tinghua Zhang MSc, Kayvan Amjadi MD
}

Abstract

Background: Tunnelled pleural catheters used to treat malignant pleural effusions may achieve pleurodesis. We aimed to identify factors associated with higher pleurodesis rates and earlier catheter removal.

Methods: We retrospectively reviewed a prospective database of tunnelled pleural catheters inserted consecutively between May 2006 and June 2013 for confirmed malignant pleural effusion. The cohort included patients who underwent medical thoracoscopy. Clinical, radiologic and pleural fluid data were recorded. We used logistic regression and Cox regression to assess rates of and days to pleurodesis, respectively.

Results: We analyzed data for 1071 tunnelled pleural catheters in 956 patients. Increased rates of pleurodesis were associated with lymphoma (odds ratio [OR] 3.49, 95\% confidence interval [Cl] 1.93-6.33), ovarian cancer (OR 2.93, 95\% Cl 1.68-5.11), Eastern Cooperative Oncology Group Scale of Performance Status grade 2 or less (OR 2.79, 95\% Cl 1.79-4.34), medical thoracoscopy (OR 2.21, 95\% Cl 1.28-3.85), protein level (OR 1.03, 95\% Cl 1.01-1.06), albumin level (OR 1.07, 95\% Cl 1.03-1.12) and percent eosinophils (OR 1.04, 95\% Cl 1.00-1.07). Reduced rates of pleurodesis were associated with gastrointestinal cancers (OR 0.41 , $95 \% \mathrm{Cl} 0.19-0.87$ ), hydropneumothorax on the postdrainage chest radiograph (OR $0.62,95 \% \mathrm{Cl} 0.41-0.94)$ and percent other cells on cell count (OR $0.98,95 \% \mathrm{Cl} 0.97-0.99$ ). Earlier pleurodesis was associated with ovarian cancer (hazard ratio [HR] 1.48, 95\% $\mathrm{Cl}$ 1.06-2.08), medical thoracoscopy (HR 1.45, 95\% Cl 1.10-1.92), protein level (HR 1.03, 95\% Cl 1.01-1.04) and percent eosinophils (HR 1.02, 95\% Cl 1.00-1.04). Delayed pleurodesis was associated with breast cancer (HR 0.61, 95\% Cl 0.46-0.81), hydropneumo-

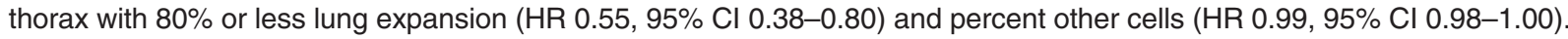

Interpretation: Clinicians should consider numerous factors to predict the probability of and timing to pleurodesis with tunnelled pleural catheters.

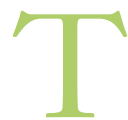
unnelled pleural catheters are an alternative to chemical pleurodesis for managing recurrent malignant pleural effusion ${ }^{1}$ and are recommended by current international guidelines. ${ }^{2,3}$ Patients can be treated as outpatients and can avoid hospital admissions associated with chemical pleurodesis. ${ }^{4}$ Tunnelled pleural catheters are also effective in the setting of trapped lung. ${ }^{5}$

Although about $46 \%$ of patients eventually achieve pleurodesis and their tunnelled pleural catheter can be removed, ${ }^{6}$ the mechanism by which this occurs is unclear. One study assessing factors that predict pleurodesis of tunnelled pleural catheters in patients with malignant pleural effusion showed increased rates of pleurodesis with the absence of chest wall irradiation, positive findings on cytologic examination, breast and gynecologic cancers, and complete reexpansion of the underlying lung.?

It is important to recognize clinical factors associated with earlier or delayed pleurodesis, as this allows physicians to personalize treatment of malignant pleural effusion. Patients also frequently ask about the duration of tunnelled pleural catheter placement. Furthermore, there are economic implications of pleurodesis timing, because tunnelled pleural catheters have ongoing drainage costs the longer they are in place. ${ }^{8}$ The present study aimed to identify clinical factors associated with higher rates of pleurodesis after insertion of a tunnelled pleural catheter and earlier catheter removal.

\section{Methods}

We performed a retrospective review of a prospectively collected database of tunnelled pleural catheters inserted for

Competing interests: None declared.

This article has been peer reviewed.

Correspondence to: Kayvan Amjadi, kamjadi@toh.ca

CMAJ Open 2018. DOI:10.9778/cmajo.20170163 
treating confirmed malignant pleural effusion at The Ottawa Hospital. We evaluated the cases of catheters that were consecutively inserted from May 2006 to June 2013. We assessed data for up to 3 years after catheter insertion to allow ample time for the catheter to achieve pleurodesis. We collected common clinically relevant variables, including baseline Eastern Cooperative Oncology Group (ECOG) Scale of Performance Status grade, baseline and transition dyspnea index, complications, pathological findings, pleural fluid analysis at the time of catheter insertion and chest radiology data. Chest radiographs were assessed at baseline, within 24 hours after catheter insertion and at catheter removal. The degree of lung expansion was recorded as more than $80 \%, 51 \%-80 \%, 30 \%-$ $50 \%$ or less than $30 \%$.

\section{Definitions of outcomes}

The primary outcomes were rates of, and days to, pleurodesis. To meet our standard definition of pleurodesis, tunnelled pleural catheters had to have minimal drainage $(<50 \mathrm{~mL})$ with 2 consecutive drainages and a lack of increase in pleural effusion size on subsequent chest radiographs. Complete pleurodesis was defined as lung expansion greater than $80 \%$ at the time of catheter removal, versus $80 \%$ or less for partial pleurodesis. Catheters removed for another reason, such as dislodgement, were excluded from the final analysis of pleurodesis. Catheters that did not meet our criteria for pleurodesis and cases in which the patient died before catheter removal were considered failure of pleurodesis.

\section{Clinical practice}

Patients with suspected or confirmed malignant pleural effusions were referred to our clinic and were assessed for tunnelled pleural catheter insertion by interventional pulmonologists. Tunnelled pleural catheters (PleurX, BD) in our centre were inserted in an outpatient clinic, in the inpatient ward or at the time of medical thoracoscopy in the endoscopy suite. Pleural fluid was drained by vacuum bottles until there was no further drainage or as tolerated by the patient. Home care nursing services were arranged to perform drainage 3 times a week up to $1 \mathrm{~L}$ maximum. All patients were followed at 2 weeks in the pleural effusion clinic, and subsequent follow-up was arranged every 8 weeks. The catheter was kept in place until the amount drained was less than $50 \mathrm{~mL}$ on 2 consecutive drainages and there was no increase in pleural effusion size on follow-up chest radiology. At catheter removal, the skin was cleaned and draped in a sterile fashion. Lidocaine was used to anesthetize the insertion site, and the catheter was dissected out and removed.

Some patients underwent outpatient medical thoracoscopy for diagnosis or tissue acquisition for ancillary testing. The procedure was performed in the endoscopy suite with moderate conscious sedation. Ultrasonographic guidance was used to mark an appropriate entry site, the skin was anesthetized with lidocaine, Kelly forceps were used to dissect to the pleural space, and an 8-mm disposable trocar was inserted. A semirigid pleuroscope (Olympus LTF-160) was inserted through the trocar, and all the fluid was aspirated. Parietal pleural abnormalities were biopsied. A tunnelled pleural cath- eter was inserted at the end of the procedure. The catheter was connected to a water seal suction device at $-20 \mathrm{~cm}$ of water, followed by $-40 \mathrm{~cm}$ of water. The catheter was disconnected when no further air leak was noted. Patients were discharged home after they had been observed for 2 hours and had a postprocedure chest radiograph that showed stable lung expansion at 2 hours.

\section{Statistical analysis}

We analyzed the data using SAS version 9.4 statistical software (SAS Institute). We determined the associations of clinical variables with pleurodesis by univariate and multivariate logistic regression for both categorical and continuous variables. We further assessed categorical variables using the $\chi^{2}$ test and compared medians using the Mann-Whitney test. Significant continuous variables by multivariate analysis were assessed by receiver operating characteristic analysis, and the highest predictive accuracy was used as the threshold value. We analyzed the associations of clinical variables with days to pleurodesis using Cox regression. Variables that were significant at a $5 \%$ significance level were retained in the final multivariate regression models. Adjusted odds ratios (ORs) and 95\% confidence intervals (CIs) were calculated.

\begin{tabular}{|lc|}
\hline $\begin{array}{l}\text { Table 1: Baseline demographic and clinical characteristics at } \\
\text { insertion of tunnelled pleural catheter }\end{array}$ \\
\hline \\
Characteristic & $\begin{array}{c}\text { No. }(\%) \text { of } \\
\text { catheters* } \\
n=1071\end{array}$ \\
\hline Patient age, yr, mean \pm SD & $68 \pm 12$ \\
\hline Patient sex & \\
\hline Male & $437(40.8)$ \\
\hline Female & $634(59.2)$ \\
\hline Side of catheter & $466(43.5)$ \\
\hline Left & $605(56.5)$ \\
\hline Right & $1(0.1)$ \\
\hline ECOG Scale of Performance Status grade & $43(4.0)$ \\
\hline 0 & $173(16.2)$ \\
\hline 1 & $395(36.9)$ \\
\hline 2 & $459(42.8)$ \\
\hline 3 & $2.2 \pm 1.9$ \\
\hline 4 & $6.4 \pm 1.6$ \\
\hline Baseline dyspnea index, mean \pm SD & $1.6 \pm 0.77$ \\
\hline Transition dyspnea index, mean \pm SD & $399(37.2)$ \\
\hline Fluid drained, L, mean \pm SD & $585(54.6)$ \\
\hline Positive findings on cytologic examination & $228(21.3)$ \\
\hline Baseline pleural effusion above hilum & $158(14.8)$ \\
\hline Hydropneumothorax after drainage & \\
\hline Medical thoracoscopy at catheter insertion & \\
\hline $\begin{array}{l}\text { Note: ECOG = Eastern Cooperative Oncology Group, SD = standard deviation. } \\
\text { *Except where noted otherwise. }\end{array}$ & \\
\hline
\end{tabular}


Table 2: Rates of pleurodesis and days to pleurodesis by tumour type in univariate analysis

\begin{tabular}{|lcccc|}
\hline Tumour type & $\begin{array}{c}\text { No. }(\%) \text { of catheters } \\
\text { with pleurodesis }\end{array}$ & OR (95\% Cl) & $\begin{array}{c}\text { Days to pleurodesis, } \\
\text { median (IQR) }\end{array}$ & $p$ value \\
\hline Non-small-cell lung cancer $(n=384)$ & $151(39.3)$ & $0.77(0.60-1.00)$ & $42(25-77)$ & 0.5 \\
\hline Breast $(n=213)$ & $90(42.2)$ & $0.95(0.70-1.28)$ & $65(35-144)$ & $<0.001$ \\
\hline Ovarian $(n=83)$ & $56(67.5)$ & $2.95(1.83-4.75)$ & $41(29-66)$ & 0.3 \\
\hline Lymphoma $(n=76)$ & $48(63.2)$ & $2.39(1.47-3.87)$ & $48(29-100)$ & 0.4 \\
\hline Gastrointestinal $(n=66)^{*}$ & $12(18.2)$ & $0.27(0.14-0.51)$ & $35(28-46)$ & 0.4 \\
\hline Mesothelioma $(n=53)$ & $32(60.4)$ & $2.07(1.18-3.63)$ & $39(16-87)$ & 0.4 \\
\hline Other $(n=196)$ & $75(38.3)$ & $0.77(0.56-1.06)$ & $42(21-62)$ & 0.9 \\
\hline Total $(n=1071)$ & $464(43.3)$ & - & $44(26-90)$ & - \\
\hline $\begin{array}{l}\text { Note: } \mathrm{Cl}=\text { confidence interval, IQR }=\text { interquartile range, OR = odds ratio. } \\
\text { *Includes esophageal, gastric and colon. }\end{array}$ & & & \\
\hline
\end{tabular}

\section{Ethics approval}

This study was approved by the Ottawa Health Sciences Research Ethics Board.

\section{Results}

We reviewed the cases of 1128 tunnelled pleural catheters. We excluded 57 catheters because of removal for mechanical failure, kinking of the tube, chemical pleurodesis or substantial missing data. Thus, 1071 catheters in 956 patients were included in the final analysis of pleurodesis. Baseline demographic and clinical characteristics are shown in Table 1.

\section{Univariate analyses}

Rates of pleurodesis and days to pleurodesis by tumour type are shown in Table 2. The overall pleurodesis rate was $43.3 \%$. Of the 464 catheters with pleurodesis, 272 (58.6\%) had complete pleurodesis and 192 (41.4\%) had partial pleurodesis. Only 15 catheters (1.4\%) had less than 50\% lung expansion at removal. The median time to pleurodesis was 44 days (interquartile range [IQR] 26-90 d). A total of 607 catheters $(56.7 \%)$ were not removed before death. Among patients who died before catheter removal, the median time to death was 38 (IQR 18-80) days. In univariate logistic regression, ovarian cancer, lymphoma and mesothelioma were associated with higher rates of pleurodesis when compared to other tumour groups. Gastrointestinal and non-small-cell lung cancers were associated with lower rates of pleurodesis.

Results of the univariate analysis on other clinical variables are shown in Table 3. Clinical factors significantly associated with higher rates of pleurodesis were ECOG Scale of Performance Status grade, medical thoracoscopy, protein level, albumin level, percent lymphocytes and percent eosinophils. Percent neutrophils and percent other cells on cell count were associated with lower rates of pleurodesis.

\section{Lung expansion and hydropneumothorax}

The interaction between degree of lung expansion and hydropneumothorax on the postinsertion chest radiograph
Table 3: Univariate logistic regression analysis of other demographic and clinical factors predicting rates of pleurodesis

\begin{tabular}{|lc|}
\hline Variable & OR (95\% Cl) \\
\hline Age & $0.994(0.985-1.004)$ \\
\hline $\begin{array}{l}\text { ECOG Scale of Performance Status } \\
\text { grade } \leq 2\end{array}$ & $5.078(3.639-7.087)$ \\
\hline Medical thoracoscopy & $5.435(3.639-8.041)$ \\
\hline Pleural infection & $2.645(0.792-8.837)$ \\
\hline Chest radiologic data & \\
\hline Hydropneumothorax & $1.091(0.812-1.464)$ \\
\hline Lung expansion $\leq 80 \%$ & $0.887(0.696-1.131)$ \\
\hline Pleural fluid analysis & $1.499(0.882-2.547)$ \\
\hline pH & $1.070(1.054-1.086)$ \\
\hline Protein level & $1.147(1.118-1.178)$ \\
\hline Albumin level & $1(1-1)$ \\
\hline Lactate dehydrogenase level & $0.993(0.943-1.046)$ \\
\hline Glucose level & $1(1-1)$ \\
\hline Erythrocyte count & $1(1-1)$ \\
\hline Total nucleated cell count & $0.990(0.984-0.997)$ \\
\hline$\%$ neutrophils & $1.016(1.011-1.021)$ \\
\hline$\%$ lymphocytes & $0.996(0.990-1.002)$ \\
\hline$\%$ monocytes & $0.999(0.988-1.011)$ \\
\hline$\%$ mesothelial cells & $1.045(1.015-1.076)$ \\
\hline$\%$ eosinophils & $0.797(0.620-1.025)$ \\
\hline$\%$ other cells on cell count & \\
\hline $\begin{array}{l}\text { Positive findings on cytologic } \\
\text { examination }\end{array}$ & \\
\hline $\begin{array}{l}\text { Note: Cl = confidence interval, EcoG = Eastern Cooperative Oncology Group, OR }= \\
\text { odds ratio. }\end{array}$ \\
\hline
\end{tabular}

was further assessed with the $\chi^{2}$ test. Among patients with hydropneumothorax after insertion, the lower the degree of lung expansion, the lower the rate of pleurodesis (Table 4). Among patients with hydropneumothorax and less than $30 \%$ 
lung expansion, 4 catheters (17\%) achieved pleurodesis. Interestingly, catheters in patients with hydropneumothorax with more than $80 \%$ expansion had higher rates of pleurodesis $(47 / 71[66.2 \%])$ than those in patients with no hydropneumothorax with more than $80 \%$ expansion $(193 / 465$ [41.5\%] $)(p<0.001)$.

\begin{tabular}{|lcc|}
\hline $\begin{array}{l}\text { Table 4: Relation of hydropneumothorax on postdrainage } \\
\text { chest radiograph with pleurodesis }\end{array}$ \\
\hline $\begin{array}{l}\text { Degree of lung } \\
\text { expansion, } \%\end{array}$ & $\begin{array}{c}\text { No. }(\%) \text { of catheters with } \\
\text { pleurodesis }\end{array}$ & $p$ value* \\
\hline$>80(n=71)$ & $47(66)$ & $<0.001$ \\
\hline $51-80(n=94)$ & $37(39)$ & 0.6 \\
\hline $30-50(n=39)$ & $8(20)$ & 0.006 \\
\hline$<30(n=24)$ & $4(17)$ & 0.01 \\
\hline${ }^{*}$ For comparison with all other inserted catheters; $\chi^{2}$ test. \\
\hline
\end{tabular}

Table 5: Multivariate logistic regression of clinical factors predicting rates of pleurodesis

\begin{tabular}{|lc|}
\hline Variable & OR $(95 \% \mathrm{Cl})$ \\
\hline Lymphoma & $3.49(1.93-6.33)$ \\
\hline Ovarian cancer & $2.93(1.68-5.11)$ \\
\hline Gastrointestinal cancer & $0.41(0.19-0.87)$ \\
\hline $\begin{array}{l}\text { ECOG Scale of Performance Status } \\
\text { grade } \leq 2\end{array}$ & $2.79(1.79-4.34)$ \\
\hline Medical thoracoscopy & $2.21(1.28-3.85)$ \\
\hline Hydropneumothorax & $0.62(0.41-0.94)$ \\
\hline Protein level & $1.03(1.01-1.06)$ \\
\hline Albumin level & $1.07(1.03-1.12)$ \\
\hline$\%$ eosinophils & $1.04(1.00-1.07)$ \\
\hline$\%$ other cells & $0.98(0.97-0.99)$ \\
\hline $\begin{array}{l}\text { Note: Cl = confidence interval, ECOG = Eastern Cooperative Oncology Group, OR }= \\
\text { odds ratio. }\end{array}$ \\
\hline
\end{tabular}

\section{Medical thoracoscopy}

More patients with catheters inserted at thoracoscopy had an ECOG Scale of Performance Status grade of 2 or less than did patients who did not undergo medical thoracoscopy $(95 / 158$ [60.1\%] v. $122 / 913$ [13.4\%], $p<0.001)$. Among patients with an ECOG grade of 2 or less, the pleurodesis rate was higher for those who underwent medical thoracoscopy than for those who did not (87.4\% [83/95] v. $63.1 \%$ [77/122], $p=0.001)$; the median time to pleurodesis for patients who underwent medical thoracoscopy was 38 (IQR 16-91) days, compared to 56 (IQR 35-96) days for those who did not $(p=0.04)$.

\section{Multivariate analyses}

Results of multivariate logistic regression analysis to investigate the relation between clinical factors and rates of pleurodesis are given in Table 5. Increased rates of pleurodesis were significantly associated with lymphoma, ovarian cancer, ECOG Scale of Performance Status grade of 2 or less, medical thoracoscopy, protein level, albumin level and percent eosinophils. Reduced rates of pleurodesis were associated with gastrointestinal cancers, the presence of hydropneumothorax on the postdrainage chest radiograph and percent other cells on cell count. Threshold values for continuous variables with the highest accuracy for predicting pleurodesis were protein level $44 \mathrm{~g} / \mathrm{L}$ or greater, albumin level $25 \mathrm{~g} / \mathrm{L}$ or greater, percent eosinophils $6 \%$ or greater, and percent other cells $0 \%$ (Table 6).

Results of the multivariate Cox regression analysis to investigate the relation between clinical factors and days to pleurodesis are shown in Table 7. Factors significantly associated with earlier pleurodesis were ovarian cancer, medical thoracoscopy, protein level and percent eosinophils. Factors associated with delayed pleurodesis were breast cancer and percent other cells on cell count. Hydropneumothorax was not significant in this model, and an alternative multivariate Cox regression was performed that combined hydropneumothorax with degree of lung expansion into 1 variable. In this final model, hydropneumothorax with $80 \%$ or less lung expansion was found to be associated with delayed pleurodesis (hazard ratio 0.55 , 95\% CI 0.38-0.80).

Table 6: Optimal threshold values by receiver operating characteristic curve analysis of continuous variables predicting pleurodesis

\begin{tabular}{|c|c|c|c|c|c|c|c|c|}
\hline Variable* & $\begin{array}{l}\text { Threshold } \\
\text { value }\end{array}$ & $\begin{array}{c}\text { Area under the } \\
\text { curve } \\
(95 \% \mathrm{Cl})\end{array}$ & $\begin{array}{l}\text { Sensitivity } \\
(95 \% \mathrm{Cl})\end{array}$ & $\begin{array}{l}\text { Specificity } \\
(95 \% \mathrm{Cl})\end{array}$ & $\begin{array}{c}\text { PPV } \\
(95 \% \mathrm{Cl})\end{array}$ & $\begin{array}{c}\text { NPV } \\
(95 \% \mathrm{Cl})\end{array}$ & PLR & NLR \\
\hline Protein level & $\geq 44 \mathrm{~g} / \mathrm{L}$ & $\begin{array}{c}0.69 \\
(0.65-0.72)\end{array}$ & $\begin{array}{c}0.45 \\
(0.41-0.50)\end{array}$ & $\begin{array}{c}0.81 \\
(0.77-0.84)\end{array}$ & $\begin{array}{c}0.63 \\
(0.57-0.68)\end{array}$ & $\begin{array}{c}0.67 \\
(0.64-0.71)\end{array}$ & 2.35 & 0.68 \\
\hline Albumin level & $\geq 25 \mathrm{~g} / \mathrm{L}$ & $\begin{array}{c}0.71 \\
(0.68-0.75)\end{array}$ & $\begin{array}{c}0.47 \\
(0.42-0.52)\end{array}$ & $\begin{array}{c}0.82 \\
(0.79-0.85)\end{array}$ & $\begin{array}{c}0.65 \\
(0.59-0.71)\end{array}$ & $\begin{array}{c}0.69 \\
(0.65-0.72)\end{array}$ & 2.64 & 0.65 \\
\hline$\%$ eosinophils & $\geq 6 \%$ & $\begin{array}{c}0.55 \\
(0.52-0.58)\end{array}$ & $\begin{array}{c}0.09 \\
(0.07-0.12)\end{array}$ & $\begin{array}{c}0.96 \\
(0.94-0.97)\end{array}$ & $\begin{array}{c}0.61 \\
(0.49-0.73)\end{array}$ & $\begin{array}{c}0.60 \\
(0.57-0.63)\end{array}$ & 2.22 & 0.95 \\
\hline$\%$ other cells & $0 \%$ & $\begin{array}{c}0.55 \\
(0.51-0.58)\end{array}$ & $\begin{array}{c}0.60 \\
(0.55-0.65)\end{array}$ & $\begin{array}{c}0.47 \\
(0.43-0.51)\end{array}$ & $\begin{array}{c}0.44 \\
(0.40-0.49)\end{array}$ & $\begin{array}{c}0.62 \\
(0.57-0.67)\end{array}$ & 1.12 & 0.86 \\
\hline
\end{tabular}




\begin{tabular}{|lc|}
\hline $\begin{array}{l}|l| \\
\text { Table 7: Multivariate Cox regression of clinical factors } \\
\text { predicting days to pleurodesis }\end{array}$ \\
\hline Variable & $\mathrm{HR}(95 \% \mathrm{Cl})$ \\
\hline Ovarian cancer & $1.48(1.06-2.08)$ \\
\hline Breast cancer & $0.61(0.46-0.81)$ \\
\hline Medical thoracoscopy & $1.45(1.10-1.92)$ \\
\hline $\begin{array}{l}\text { Hydropneumothorax with } \leq 80 \% \\
\text { lung expansion }\end{array}$ & $0.55(0.38-0.80)$ \\
\hline Protein level & $1.03(1.01-1.04)$ \\
\hline$\%$ eosinophils & $1.02(1.00-1.04)$ \\
\hline$\%$ other cells & $0.99(0.98-1.00)$ \\
\hline Note: $\mathrm{Cl}=$ confidence interval, $\mathrm{HR}=$ hazard ratio. \\
\hline
\end{tabular}

Table 8: Complications related to tunnelled pleural catheter

\begin{tabular}{|lc|}
\hline Complication & No. (\%) of catheters \\
\hline Loculation needing fibrinolytic & $45(4.2)$ \\
\hline Catheter dislodged & $16(1.5)$ \\
\hline Pleural infection & $13(1.2)$ \\
\hline $\begin{array}{l}\text { Symptomatic reexpansion pulmonary } \\
\text { edema }\end{array}$ & $13(1.2)$ \\
\hline Leak at catheter site & $7(0.6)$ \\
\hline Cellulitis & $6(0.6)$ \\
\hline Pain necessitating removal & $4(0.4)$ \\
\hline Mechanical failure & $3(0.3)$ \\
\hline Catheter plugged & $3(0.3)$ \\
\hline Tumour seeding & $2(0.2)$ \\
\hline Broken catheter valve & $2(0.2)$ \\
\hline Syncope & $1(0.1)$ \\
\hline Catheter fractured at removal & $1(0.1)$ \\
\hline
\end{tabular}

\section{Complications}

The study complications are listed in Table 8 . The most common complications were loculation requiring a fibrinolytic (4.2\%), dislodgement of the catheter $(1.5 \%)$ and pleural infection $(1.2 \%)$. Fibrinolytic use was not associated with pleurodesis. One patient had a fractured and retained catheter, which occurred when the patient tried to remove it herself. There were no cases of death associated with catheter insertion. Thirty-two patients (3.3\%) had recurrence of pleural effusion after catheter removal and needed catheter reinsertion.

\section{Interpretation}

We found that patients who had combined medical thoracoscopy and tunnelled pleural catheter insertion had significantly higher pleurodesis rates and earlier catheter removal than patients with only catheter insertion. The observed rate of pleurodesis appears to be comparable to, if not greater than, reported rates for chemical pleurodesis. ${ }^{3}$ We believe that pleu- ral biopsy, minor bleeding and introduction of air into the pleural space result in inflammation and facilitate pleurodesis. Combined insertion of a tunnelled pleural catheter and medical thoracoscopy has been described and facilitates safe same-day discharge. ${ }^{9,10}$ Medical thoracoscopy may also be combined with talc pleurodesis ${ }^{11}$ if earlier pleurodesis is desired or if catheter removal is expected to be delayed. Combined outpatient medical thoracoscopy and insertion of a tunnelled pleural catheter should be strongly considered as the diagnostic and therapeutic approach for patients suspected to have malignant pleural effusion in whom the cytologic findings are nondiagnostic and for those in whom more tissue is required for ancillary testing.

As expected, patients with hydropneumothorax after insertion of a tunnelled pleural catheter had lower pleurodesis rates than those without hydropneumothorax, likely owing to the presence of trapped or entrapped lung. However, patients with hydropneumothorax and more than $80 \%$ lung expansion had higher pleurodesis rates than patients with no hydropneumothorax and more than $80 \%$ lung expansion in univariate analysis. One explanation for this finding is that the inflammatory pleural process that results in lung entrapment is the same process that results in pleurodesis, and adequate lung expansion allows the potential for adequate visceral and parietal pleural apposition. The mediastinum and diaphragm may shift slightly to facilitate pleural apposition. The simple presence of air in the pleural space may contribute to an inflammatory process to facilitate pleurodesis. Pneumothorax is a known cause of eosinophilic effusion, ${ }^{12}$ and pleural eosinophils were associated with successful pleurodesis in our study. Patients with hydropneumothorax and $80 \%$ or less lung expansion had delayed catheter removal. This finding may be explained by the fact that the pleural space of nonexpanding lungs continues to reaccumulate fluid after fluid removal. Eventually there is partial pleurodesis, loculation may develop, and the catheter stops draining.

We found that lymphoma and ovarian cancer were associated with higher pleurodesis rates in multivariate analysis. Ovarian cancer was associated with earlier catheter removal. Although breast cancer was not associated with higher pleurodesis rates, it was associated with delayed pleurodesis. These findings may reflect varying responses to chemotherapy. For example, patients with lymphoma or ovarian cancer may have an effective and rapid response, whereas those with breast cancer may have a delayed response. The type of systemic therapy may also have an impact. For example, patients with metastatic breast cancer are often treated with endocrine therapy, which may result in slower responses than chemotherapy..$^{13}$ Similarly, patients with lower ECOG Scale of Performance Status grades had higher pleurodesis rates than did patients with higher grades, possibly related to chemotherapy, in addition to surviving long enough to allow pleurodesis to occur.

Our findings that breast cancer and positive results on cytologic examination were not associated with increased pleurodesis rates are discrepant with the results of a smaller study conducted between 1998 and 2006. In fact, we found that breast cancer was associated with delayed catheter removal. The discrepancy may be related to differences between the cohorts in the use of chemotherapy or to the advent of newer targeted 
therapies, such as trastuzumab. ${ }^{14}$ Alternatively, the difference may be due to statistical chance. In our study, positive cytology findings approached statistical significance (OR 0.797, 95\% CI 0.620-1.025). The discrepancy may be due to the fact that our study included cytology results only at the time of catheter insertion and not at the time of prior thoracentesis. Also, the percent other cells on the cell count in our study was associated with reduced rates of pleurodesis and delayed pleurodesis. Percent other cells is nonspecific but may suggest the presence of malignant cells in the pleural fluid, although insufficient in number to confirm malignant pleural disease. Regarding fluid analysis, we found that pleural protein level and percent eosinophils predicted higher pleurodesis rates and earlier pleurodesis. The predictors of failed chemical pleurodesis in prior studies included low $\mathrm{pH},{ }^{15,16}$ lung cancer and tumour burden. ${ }^{17}$ The differences in predictive variables between chemical pleurodesis and that achieved with tunnelled pleural catheters suggest different mechanisms of pleurodesis.

\section{Limitations}

Our study has several limitations. First, many patients died before the outcome of catheter removal was reached. Thus, true pleurodesis rates may have been underestimated. This may explain why the pleurodesis rate in patients with gastrointestinal cancer was only $18 \%$. Second, although it is possible that our patients had catheter removal related to chemotherapy effect, we believe that many of these patients still achieved pleurodesis, because the rate of recurrence of pleural effusion was only $3 \%$. Third, there were other, complex variables not assessed, such as timing and types of chemotherapy and radiotherapy, anti-inflammatory therapy and nonroutine blood tests such as those for inflammatory markers. Future studies assessing these variables may be useful.

\section{Conclusion}

Clinicians must consider numerous factors to predict the likelihood of and timing to pleurodesis with tunnelled pleural catheters. In the current study, medical thoracoscopy, ECOG Scale of Performance Status grade of 2 or less, lymphoma, ovarian cancer, protein level, albumin level and percent eosinophils all predicted higher pleurodesis rates. Gastrointestinal cancer, hydropneumothorax on the postdrainage chest radiograph and percent other cells on cell count predicted lower pleurodesis rates. Earlier pleurodesis was associated with medical thoracoscopy, ovarian cancer, higher pleural protein level and percent eosinophils. Delayed catheter removal was associated with breast cancer, hydropneumothorax with $80 \%$ or less lung expansion and percent other cells on cell count. In patients who require tissue biopsy, we favour combined outpatient medical thoracoscopy and tunnelled pleural catheter insertion. In patients who are expected to have a lower probability of pleurodesis or to keep their catheter for a longer duration, chemical pleurodesis could be considered. Future comparative studies factoring in predic- tors of pleurodesis should be done to predict costs between different approaches in managing malignant pleural effusion.

\section{References}

1. Davies HE, Mishra EK, Kahan BC, et al. Effect of an indwelling pleural catheter vs chest tube and talc pleurodesis for relieving dyspnea in patients with malignant pleural effusion: the TIME2 randomized controlled trial. $7 A M A$ 2012;307:2383-9.

2. Simoff MJ, Lally B, Slade MG, et al. Symptom management in patients with lung cancer: diagnosis and management of lung cancer, 3rd ed: American College of Chest Physicians evidence-based clinical practice guidelines. Chest 2013; 143(Suppl):e455S-97S.

3. Roberts ME, Neville E, Berrisford RG, et al.; BTS Pleural Disease Guideline Group. Management of a malignant pleural effusion: British Thoracic Society Pleural Disease Guideline 2010. Thorax 2010;65(Suppl 2):ii32-40.

4. Fysh ETH, Waterer GW, Kendall PA, et al. Indwelling pleural catheters reduce inpatient days over pleurodesis for malignant pleural effusion. Chest 2012;142:394-400.

5. Pien GW, Gant MJ, Washam CL, et al. Use of an implantable pleural catheter for trapped lung syndrome in patients with malignant pleural effusion. Chest 2001;119:1641-6.

6. Van Meter ME, McKee KY, Kohlwes RJ. Efficacy and safety of tunneled pleural catheters in adults with malignant pleural effusions: a systematic review. $f$ Gen Intern Med 2011;26:70-6.

7. Warren WH, Kim AW, Liptay MJ. Identification of clinical factors predicting PleurX catheter removal in patients treated for malignant pleural effusion. Eur 7 Cardiothorac Surg 2008;33:89-94.

8. Penz ED, Mishra EK, Davies HE, et al. Comparing cost of indwelling pleural catheter vs talc pleurodesis for malignant pleural effusion. Chest 2014;146: 991-1000.

9. DePew ZS, Wigle D, Mullon JJ, et al. Feasibility and safety of outpatient medical thoracoscopy at a large tertiary medical center: a collaborative medical-surgical initiative. Chest 2014;146:398-405.

10. Kyskan R, Li P, Mulpuru S, et al. Safety and performance characteristics of outpatient medical thoracoscopy and indwelling pleural catheter insertion for evaluation and diagnosis of pleural disease at a tertiary center in Canada. Can Respir 7 2017;2017:9345324.

11. Reddy C, Ernst A, Lamb C, et al. Rapid pleurodesis for malignant pleural effusions: a pilot study. Chest 2011;139:1419-23.

12. Adelman M, Albelda SM, Gottlieb J, et al. Diagnostic utility of pleural fluid eosinophilia. Am 7 Med 1984;77:915-20.

13. Wilcken N, Hornbuckle J, Ghersi D. Chemotherapy alone versus endocrine therapy alone for metastatic breast cancer. Cochrane Database Syst Rev 2003;(2): CD002747.

14. Harries M, Smith I. The development and clinical use of trastuzumab (Herceptin). Endocr Relat Cancer 2002;9:75-85.

15. Heffner JE, Nietert PJ, Barbieri C. Pleural fluid $\mathrm{pH}$ as a predictor of pleurodesis failure: analysis of primary data. Chest 2000;117:87-95.

16. Yildirim H, Metintas M, Ak G, et al. Predictors of talc pleurodesis outcome in patients with malignant pleural effusions. Lung Cancer 2008;62:139-44.

17. Bielsa S, Hernández $\mathrm{P}$, Rodriguez-Panadero $\mathrm{F}$, et al. Tumor type influences the effectiveness of pleurodesis in malignant effusions. Lung 2011;189:151-5.

Affiliations: Division of Respirology (Li), Department of Medicine, University of Alberta, Edmonton, Alta.; Division of Respirology ( $\mathrm{Li}$, Mulpuru, Amjadi), Department of Medicine, The Ottawa Hospital, General Campus; Division of Respirology (Graver, Hosseini), Department of Medicine, Queensway Carleton Hospital; The Ottawa Hospital (Cake, Kachuik); Ottawa Methods Centre (Zhang), The Ottawa Hospital Research Institute, Ottawa, Ont.

Contributors: Pen Li, Kayvan Amjadi and Alison Graver contributed to the study conception and design. Pen Li, Alison Graver, Sarah Hosseini, Lorraine Cake, Lynn Kachuik and Kayvan Amjadi contributed to data collection. Pen Li, Sunita Mulpuru and Tinghua Zhang contributed to data analysis. Pen Li interpreted the data and drafted the manuscript. All of the authors contributed to revising the manuscript for important intellectual content, gave final approval of the version to be published and agreed to be accountable for all aspects of the work.

Supplemental information: For reviewer comments and the original submission of this manuscript, please see www.cmajopen.ca/content/6/2/ E235/suppl/DC1. 